\title{
On the New Features of Online Film and TV Subtitle Translation in China
}

\author{
Yuyong $\operatorname{Lv}^{1} \& \operatorname{Min} \operatorname{Li}^{1}$ \\ ${ }^{1}$ School of Foreign Languages, Jiangsu University, Zhenjiang, Jiangsu, China \\ Correspondence: Yuyong Lv, English Department, School of Foreign Languages, Jiangsu University, No. 301, \\ Xuefu Road, Jingkou District, Zhenjiang212013, Jiangsu Province, China. E-mail: 1973909678@qq.com
}

Received: October 7, 2015 Accepted: October 27, 2015 Online Published: November 30, 2015

doi:10.5539/ijel.v5n6p122 URL: http://dx.doi.org/10.5539/ijel.v5n6p122

This research was financed by MOE (Ministry of Education in China) Project of Humanities and Social Sciences (Project No. 12YJC740047).

\begin{abstract}
The advent and popularity of the Internet offers people all over the world easier, quicker and cheaper access to foreign movies and TV programs. The Chinese audience's increased demand for online subtitled foreign movies and TV has brought many new changes to the traditional field of subtitle translation. This paper, by collecting and studying many cases of online subtitled English movies and TV in China, has found some changes in the main features of the subtitle translation on the Internet, such as the de-professionalization of the subtitle translators, a wider choice of translation strategies, the audience's longing for active participation and interaction and the extended functions of subtitles. A study of these new changes is intended to be of value to the adaptation and development of film and TV translation in the new media age.
\end{abstract}

Keywords: the Internet era, online film and TV subtitle Translation, changes, new features

\section{Introduction}

\subsection{Research Background}

The advent of the Internet has completely transformed the ways of spreading and enjoying foreign movies and TV programs worldwide. It offers people all over the world easier, cheaper and quicker access to foreign movies and TV programs. Due to the changes of the media and the promotion of cultural exchanges, the Chinese audience's appreciation of the imported English movies and TV has undergone some changes in many aspects. Especially in recent years, an increasing number of Chinese audiences prefer subtitled versions to dubbed versions since they long for the foreignness and cultural idiosyncrasies preserved in the original voice and subtitle. Watching subtitled versions has become many young Chinese people's dominant way of enjoying foreign movies or TV. Changes like this in turn call for changes in subtitle translation. However, the previous studies pay too much attention to dubbing-oriented subtitle translation or subtitling in the cinema or on TV (Qian, 2000; Li, 2001; Chai, 2006; Zhao, 2006; Lv \& Li, 2013; Herbst, 1995; Karamitroglou, 1998; Diaz-Cintas, 2007). Few studies attach much importance to the changes in subtitle translation online and the needs of online TV or movie viewers (Diaz-Cintas, 2006). By studying many cases of subtitled English movies and TV in China, the present paper tries to find out and summarize the new features in the subtitle translation on the net and holds that it is quite necessary and worthy to highlight the changes so as to inspire the research of subtitle translation in the new era.

\subsection{Literature Review}

Western scholars started the study of film and TV translation quite early. The early studies are mainly descriptive without highlighting the particularities of screen translation. With the rapid development of film and TV industry in the $20^{\text {th }}$ century, relevant translation studies began to make large strides in the 1980s and 1990s. In the past decades, western studies have covered every possible aspect of audio visual translation from various perspectives and many research methods have been adopted, especially, the method of case study. Translation strategies studies in dubbing and subtitling have been conducted by referring to various theories such as text analysis, pragmatics, reception theory, relevance theory and so on (Whitman-Linsen, 1992; Nedergaard-Larsen, 1993; 
Zabalbeascoa, 1994 \& 1996; Herbst, 1995; Gottleib, 1993; Diaz-Cintas, 2007).

In China, Qian Shaochang, a famous translator, pointed out the importance of film translation and called for more attention to it in 2000. With more attention being paid to this field, Chinese scholars have mainly focused on film and TV translation principles and strategies (Zhang, 1998; Li, 2001; Ma, 2012). Other scholars have conducted case studies of some famous films by referring to some translation theories or theories from other fields, such as relevance theory or polysystem theory and so on (Wang, 2007).

However, few studies have attached much importance to the new trends in film and TV translation $(\mathrm{Lv} \& \mathrm{Li}$, 2013; Diaz-Cintas, 2006). The popularity of the Internet and new digital technologies in the new era calls for attention to changes in online film and TV translation and the needs of online film and TV viewers. That's where this paper comes in.

\section{Methodology}

This present study focuses on making a comparison and contrast between traditional dubbing or subtitling practice and online subtitling so as to deduce the new features of subtitle translation in the new era. In this study, the basic research questions are as follows:

1). What new demands do the online viewers have for subtitle translation in the Internet era?

2). How do the new media and new needs of online viewers affect the subtitle translators, their choice of translation strategies and the functions of subtitle?

With these basic questions in mind, the study adopts an analytical and inductive approach by collecting and making case studies of about ten popular Chinese subtitled versions of American movies and TV series, such as The Big Bang Theory, CSI: Crime Scene Investigation, Friends, 2 Broke Girls, Men in Black III, Madagascar III and so on from various aspects, such as the translators, online viewers and translation strategies.

It should be added as a footnote here that some facts need to be clarified in advance. Although "regardless of ethics, or motive, fansubs are technically illegal" (Diaz-Cintas \& Sanchez, 2006, p. 45), those amateur online translators and their translation styles have affected the online translators of some licensed video websites and are also quite popular among the viewers. They are part of net film and TV subtitle translators discussed in this paper, although mostly the present paper focuses more on legal net subtitle translation.

\section{New Features of Online Film and TV Subtitle Translation in China}

\subsection{The De-Professionalization of Subtitle Translators on the Internet}

For a long time, the main body of subtitle translators in China is composed of professional translators from dubbing factories, TV stations and movie or TV manufacturing companies as well as some professors and scholars from universities and colleges. Most of the professional translators have undergone strict training in the relevant field and are equipped with cross-cultural awareness, specialized knowledge and language expertise. They have translated many excellent foreign movies, so they are experienced in subtitle translation. University scholars are not only actively involved in subtitle translation practice but also are engaged in relevant theoretical research (Xiao \& Peng, 2014). On the one hand, their translation has fully showcased the artistry and charm of the original movies or TV shows. On the other hand, their translation must also be in the interest of China so as to cross the barriers set by film or TV censorship. In other words, their translation will "respect the foreign culture, serve Chinese people's habit of appreciation and, what's more, take the safety of Chinese culture into consideration." (Zhang, 2002, p. 147) So they have served as the role of a "gate-keeper" and have the discursive power. They have such a strong voice in this field that they have the right to change, delete or even manipulate the scripts. For example, they will change some obscenities or delete some porn, violent or criminal clips and so on. For some viewers, their translation is under so many restrictions that they have distanced themselves from ordinary audience. Especially, in the Internet age, the audience needs translators to convey authentic meaning to them more than ever. That's why their translation has received increasing criticism from the audience in recent years.

The advent of new media such as the Internet changes this situation and gives every ordinary person a chance to make his voice heard. Especially the ordinary people with bilingual proficiency and bicultural background can get a chance to translate subtitles for some video websites or form their own team known as fansub groups or fansubbers. These net subtitle translators are young people from all walks of life and they embrace foreign cultures and take the lead in the popular culture. They are mostly faithful fans of foreign movies or TV programs. So quite unlike professional translators, they take the role of both audience and translator and tend to adopt a de-professional translation style. Although they still put emphasis on accuracy and fluency, they give more 
priority to what the audience needs and strive for getting closer to the audience. They know very well that modern Chinese audience are quite ready to embrace the foreignness or alterity in the original movies or programs, so they never manipulate the target texts and remain invisible so as to convey the most original and authentic meaning to the audience. At present, grassroots translators are better received by the netizens than the professional translators (Pan, 2007).

\subsection{A Wider Range of Subtitle Translation Methods at the Service of Net Subtitle Translators}

Before the popularization of subtitled movies or TV programs, most subtitle translation was dubbing-oriented. Therefore, the dubbing-oriented subtitle translation has unavoidably been constrained by all the factors related to dubbing such as time, space, the synchronization between sound and scene or the shape of actor's or actress' mouth, pause and body gestures and so on. Besides, the dubbing-oriented subtitle translation is for speaking, so the target text should be "listening-friendly, integrative, transient, easily accepted and free of notations" (Qian, 2000, p. 61). Therefore, under so many constraints, the dubbing-oriented subtitle translation, also known as the constrained translation or condensed translation (Nedergaard-Larsen, 1993), mostly adopts the strategy of reduction, which mainly includes three methods: condensation, reductive paraphrasing and deletion. However, with the popularity of subtitled movies or TV, "subtitle translation has undergone the transition from spoken style to written style" ( $\mathrm{Li}, 2001$, p. 38). Since the target subtitled version is written, visual and free from many restrictions, more translation strategies are at the service of subtitle translators.

As an increasing number of new media spring up, subtitles can be replayed anytime and many times instead of being transient. Therefore, many net subtitle translators hold that time and space should not be the major constraints for subtitle translation any more. This undoubtedly has given them more freedom in choosing translation strategies. Besides the strategy of deduction most commonly adopted in dubbing-oriented subtitle translation, net subtitle translators also employ the following strategies:

1). To localize or popularize the translation to get closer to the audience. In order to cater to the taste of young viewers and make the targeted version more easily accepted in China, net subtitle translators venture to use local or popular Chinese-specific elements such as Chinese proverbs, proper names, dialects, slang, or colloquialisms and even Chinese social and network catchwords, which, when used aptly, can add humor to the target version and render it more approachable. For example:

(1) "I swear to God"

Translation: “我向毛主席保证”. (literal meaning: I swear to Chairman Mao)

(2) "I'm back"

Translation: “我胡汉三又回来了”. (literal meaning: I, Hu Hansan, is back)

\section{(3) “I wasn't even listening”}

Translation: “我是路过打酱油的”. (literal meaning: I'm only passing by on my way to buy soy sauce.)

In the first version above, “我向毛主席保证” is a very popular Chinese expression because Chairman Mao, as the founder of new China, is always acclaimed as a hero or even god by the Chinese people. In the second example, “我胡汉三又回来了”, a famous movie line in China, makes the translation more striking and interesting. The third version, “路过打酱油”, which means “paying no attention” or “none of my business”, is a popular network catchword. The use of these expressions unique to China in the target versions can not only convey the exact meaning, but also add something familiar, local and humorous to the translation. This practice is especially popular among young viewers. By doing this, these net subtitle translators have struck such a balance between the foreignness and localization that their translation has always brought lots of surprises to the audience and kept them refreshed.

2). To add detailed notations or explanations to bridge the cultural gap. On the one hand, net translators prefer the strategy of localization to shorten or bridge the distance between the foreign movies or TV and the audience. On the other hand, they strive to retain the foreign or exotic culture to the maximum in the target text. While dealing with English culturally-loaded words, such as English proverbs, idioms, puns, games of words, allusions and so on, net subtitle translators no longer simply delete them or retain their meaning, as professional translators do. Instead, they mostly adopt literal translation plus notes and explanations to help the audience better appreciate the foreign culture and retain the integrity of the plot. For example, the popular American TV series The Big Bang Theory and CSI: Crime Scene Investigation and so on all involve lots of subject-specific terminology, which are also the highlights of those TV series. In order to help the audience better understand the plot, net subtitle translators add lots of notes or explanations to clarify those technical terms in the contexts. 
Adding notations or explanations is no easy task. This requires the translators to be both well knowledged in the relevant subject and highly devoted to this job. Besides, they should also know how far they can carry this practice in case that the audience will get bored and tired of the tediousness of those notations or explanations.

3). To insert comments or complaints in subtitles to interact with the audience. Most net translators choose to translate a movie often because they are loyal fans of that movie. So while translating their favorite movie, they can't help commenting on the plot and the acting of an actor or actress, or even never refrain from complaining about the difficulty in rendering the meaning into the target language. Sometimes, when they find it impossible to render a sentence, they are so capricious that they simply leave it untranslated by leaving the English line where it is or telling the audience "I can't translate this line" directly. This practice is almost impossible for professional translators. However, it is such a common practice among net subtitle translators that the net audience are quite used to it and can understand them very well and even resonate with them. When they read the translators' comments or complaints or even untranslated lines, they will talk with the translators at some forums, showing their sympathy or offering their suggestions. Quite unexpectedly, some net subtitle translator groups, esp, some fansub groups become quite popular only because their translation together with their complaints or comments makes the audience feel more involved in the translation process.

All the translation methods mentioned above share something in common. They can produce humorous, witted and well-received versions, and bring the foreign movies or TV closer to the Chinese audience. Those methods, compared with traditional subtitle translation methods, are more popular among net movie or TV viewers and are also instantly recognizable as peculiar to net subtitle translators.

\subsection{The Audience' Longing for Active Involvement in What They See}

Old media like cinema or television reduced the audience to a rather passive role while seeing a movie or TV program. The mode of transmission is top-down, which means the audience don't have much freedom of choice, not to mention feedback their acceptance or suggestions to translators. The audience are no more than passive receivers of what they see.

The Internet era has fundamentally transformed the audience's way of enjoying a movie or TV. They can choose whatever they like online and communicate with their fellow viewers. According to the research on most firm American TV series fans in China (Cao \& He, 2012), they are most young people, who have good English competence and are well-educated. They are used to online communication, learning and entertainment. They are enthusiastic followers of net culture and popular culture. The highly efficient and timely net subtitle translation can better meet their needs. They are more accustomed to interacting with subtitle translators online about the plot, translation and English learning, so as to increase their sense of involvement. The localized subtitle translation methods, considerate notations and explanations, unexpected complaints, teasing and comments bring the audience and the translators closer, creating a sense of belonging. Besides, the tense competition between the video websites for the best Chinese version of a certain English movie or TV series offers the audience a wider choice, rendering them from passive receivers to active choosers. Under the influence of the net subtitle translation style, the traditional subtitle translation begins to receive more cold shoulders in China. For example, the famous American TV series Desperate Housewives has swept China when it was first released online. However, when it was showed on CCTV, China's largest, most authoritative TV channel, the audience rating was only $0.4 \%$. One of the reasons why it met its waterloo on CCTV is that CCTV showed it nearly one year later than the Internet. Besides, many audience find its subtitle translation quite rigid and feel quite unhappy about the deletions of many sensitive plots or languages done by CCTV. This case fully demonstrates that in the Internet era, the audience feel ready to embrace all the aspects of the original version, which is also what the net translators try to convey and retain.

\subsection{The Greatly Extended Functions of Subtitle Translation}

In the past, interlingual subtitles mainly helped the audience clear up language barriers and offer information ( $\mathrm{Li}$, 2001). Now with the further development of new media and the quickening of the globalization, cross-cultural transmission and exchanges are furthered. The translating of net subtitle translators begins to go beyond only switching between two languages so that the functions of subtitle translation have been enormously extended.

In the Internet age, subtitle has become a multi-functional subtitle package which can help clear up language barriers, transmit foreign cultures, facilitate English learning, entertain the audience, share and offer more educational materials and so on. The online timely and efficient subtitle services help the audience who don't understand English understand the foreign movies or TV better, and make the latest foreign movies and programs available without time lag. The detailed explanations and notations make the Chinese audience understand the foreign culture better so as to strengthen cultural communications and raise cultural tolerance. 
The humorous, close-to-the-audience and localized subtitle translation style make the audience feel more amused and entertained. Many successful translations have been so popular among the audience that they are recited and imitated again and again. The comments and complaints accompanying the subtitles as well as the interaction between the translators and the audience at the forums have greatly enhanced the sharing and interacting function of the subtitle, making the two-way communication between the audience and translators possible. Language learning-oriented subtitles on the Internet, such as bilingual subtitles and multichannel subtitle switching system, helps the audience learn the languages involved. Besides, the scope of the subtitle services has been greatly expanded. For example, the subtitled online courses from many famous foreign universities are gaining increasing popularity among online learners and the subtitle services give them easier access to excellent foreign education sources. In a sense, the pressure caused by the unbalanced distribution of excellent education sources has been eased greatly. The open, equal and sharing spirits of the Internet have been fully demonstrated in the net subtitle translation, so that subtitles are taking on more functions than ever to meet the new needs of the new age.

\section{Conclusion}

The Internet age is here regardless of human beings' will. What we can do is to go with the trend and study how to make better use of its strong points to push forward the subtitle translation practice and research. The new changes brought by the Internet age to online subtitle translation surely offer much thought for the reform and innovation of the subtitle translation in the future. In a sense, the changes in the translators, the audience and media are changing the criteria of movie and TV translation.

On the other hand, the subtitle translation in the new era should also beware of the weak points of the Internet. For example, the arbitrariness of the net will influence net subtitle translation. On the Internet, subtitle translators don't have to make their identity known to the public. Such an invisible working environment and identity have given them too much freedom to have their own way and display their individuality. They will feel no restraints in choosing translation strategies. Sometimes their translation will carry the entertaining function too far, which has received wide criticism from the audience too. Therefore, in the new age, online subtitle translation calls for new standards and disciplines which can guide it to develop more healthily.

\section{References}

Cao, S. L., \& He, W. (2012). Who are American Movie Fans - the Appreciation and Acceptance of Online American Movies by the Chinese Audience. Journal of International Communication, (9).

Chai, M. P. (2006). Translation Strategies for the Sound-Scene Synchronization of Dubbing and Subtitle. Shandong Foreign Language Teaching Journal, (1).

Diaz-Cintas, J., \& Aline R. (2007). Audiovisual Translation: Subtitling. Manchester \& Kinderhook (NY): St. Jerome Publishing.

Diaz-Cintas, J., \& Sarchez, P. (2006). Fansubs: Audiovisual Translation in an Amateur Environment. Journal of Specialized Translation, (6).

Du, Z. F., Li, Y., \& Chen, G. (2013).Basic Literacy in AV Translation \& Research. Hangzhou: Zhejiang University Press.

Gottlieb, H. (1993). Subtitling: People Translating People. In C. Dollerup \& A. Lindenaard (Eds.), Teaching Translation and Interpretation 2-Insights, Aims, Visions. Amsterdam: John Benjamins.

Herbst, T. (1995). People Do Not Talk in Sentences: Dubbing and the Idiom Principle. In Y. Gambier (Ed.), Audiovisual Communication and Language Transfer, Translation - FIT Newsletter.

Karamitroglou, F. (1998). A Proposed Set of Subtitling Standards in Europe. Translation Journal, (2).

Li, Y. X. (2001). Strategies for Translating Subtitles. Chinese Translators Journal, (4).

Lv, Y. Y., \& Li, M. (2013). On the Entertainment-oriented Rewriting in the Subtitle Translation of English Movies. Chinese Translators Journal, (3).

Ma, Z. Q. (2012). On Film and TV Translation Methods. Modern Communication, (3).

Nedergaard-Lasen, B. (1993). Culture-Bound Problems in Subtitling. Perspectives: Studies in Translatology, (2).

Pan, N. (n.d.). A Review on Imported TV Series in China. http://rirt.cuc.edu.cn/html/meijieyanjiu/2007/1101/402.html

Qian, S. C. (2000). AV Translation-A More and More Important Field in Translation. Chinese Translators 
Journal, (1).

Wang, R. (2007). On Film Subtitle Translation Strategies from the Perspective of Relevance Theory-A Case Study on the Film Gone with the Wind. Journal of Beijing International Studies University, (2)

Whitman-Linsen, C. (1992). Through the Dubbing Glass: The Synchronization of American Motion Pictures into German, French and Spanish. Frankfurt am Main: Peter Lang.

Xiao, W. Q., \& Peng, W. Q. (2014). Language Hybridization, Cultural Translation and Curriculum Construction-A Review on China First AV Translation Research Forum. Journal of Foreign Languages, (1).

Zabalbescoa, P. (1994). Factors in Dubbing Television Comedy. Perspectives: Studies in Translatology, (1).

Zhang, C. B. (1998). A Tentative Study of Film and TV Translation. Chinese Translators Journal, (2).

Zhang, Z. Y. (2002). Import to Create-A Study on Dubbed Movies and TV Dramas by CCTV International Department. China Communication Forum. Beijing: Communication University of China Publishing House.

Zhao, S. M. (2006). The Switching of Cross-cultural Information in the Subtitle Translation of Film and TV Translation. Journal of Hefei University of Technology (Social Science Edition), (4).

\section{Copyrights}

Copyright for this article is retained by the author(s), with first publication rights granted to the journal.

This is an open-access article distributed under the terms and conditions of the Creative Commons Attribution license (http://creativecommons.org/licenses/by/3.0/). 